of extensive air showers produced by ultrahigh-energy cosmic rays. By studying air Cerenkov pulse profiles and amplitudes along with other observations, it is becoming possible to understand the charge composition of primary cosmic rays at energies greater than $10^{15} \mathrm{eV}$ (Rao, Tata Institute; Tanahash, University of Tokyo; Clay, University of Adelaide; Turver).

Further progress in this discipline requires the development of new and more sensitive detection techniques. Improvement in angular resolution will lead to improved minimum flux sensitivities; such improvement may come from the imaging systems being developed independently at the Crimean and Whipple Observatories. Since the sources so far detected include an $\mathrm{X}$-ray binary, pulsars and a radio galaxy, a small improvement in sensitivity could lead to a dramatic increase in the number of detected sources (Gursky, Naval Research Laboratory). With the development in this decade of more sensitive detectors at satellite $\gamma$-ray energies and of new experiments in neutrino astronomy, the role of the atmospheric Cerenkov technique in covering this window in the electromagnetic spectrum will become all the more important.

\section{Greek fireworks}

\author{
from M.H. Day
}

THE Third European Congress of Anthropology was held in Greece at Petralona, near Thessalonika, at the end of September. Two main themes - the presapiens stage of human evolution and the biology of migrating populations attracted great interest and over 200 delegates from around thirty countries took part. One individual dominated the whole gathering, however, and that was Petralona man himself; unfortunately he was not present at the Congress since his fate was then still in the hands of the Greek courts of law. Until the courts decide whether to accede to Aris Poulianos's request that the skull be transferred to his museum at the Petralona cave, the Petralona skull remains aloof and incarcerated in its present resting place at the University of Thessalonika museum.

The first two days of the meeting were held at the Petralona site itself, in the splendid new facilities that have been provided by the energy and dedication of Poulianos, including a new tarmac road, a conference hall, a museum and laboratories. The Petralona cave nearby must be one of the most beautiful caves in Europe with hundreds of metres of vaulted galleries with stalactites and stalagmites; the cave is well illuminated and now engineered with walkways. Delegates wandered in and out of the cave freely and were shown anything that they wished to see.

The problems and the scientific disputes over Petralona man are of long standing and now rest principally upon the dating. Indeed, the conference was preceded by a brisk exchange of views on this subject in the pages of this journal ${ }^{1-5}$. The skull itself, billed as 'The Oldest Europaeoid' has features that make it crucial to establish its

M.H. Day is Professor at the Department of Anatomy, St Thomas's Hospital Medical School, Lambeth Palace Road, London SEI $7 E H$. evolutionary position.

So muddy have the waters become that almost everything ever stated about the find and the site has been questioned, yet there are some facts that seem to have a solid consensus of support. First, there seems no doubt that at Petralona in 1960 a virtually complete fossil skull was found adherent to the cave wall. Second, the cave is a Pleistocene cave containing an extinct fauna. Third, it does have a stratigraphy that is long and complex. Fourth, there are numerous supposed 'tools' made of bone, limestone, bauxite or quartz. The vast majority of these 'tools' cannot be proved to be artefacts - but some of the quartz tools are undoubtedly humanly worked. Lastly, the cave has clearly been closed for a long time but it is unlikely that any cave would remain closed for $500,000 \mathrm{yr}$ as has been claimed.

This brings us face to face with the problem of dating. Most now agree that the initial estimate of $70,000 \mathrm{yr} \mathrm{BP}$ is too young and that on a variety of grounds a date in excess of $200,000 \mathrm{yr}$ BP is more likely. The dating claimed by Poulianos of over $700,000 \mathrm{yr}$ BP for the skull is very hard to accept on the evidence produced at this meeting. Perhaps the most impressive speakers on dating were $M$. Ikeya, the originator of ESR dating, and $\mathrm{Dr}$ Yokoyama. The consensus of their views would seem to be that 400,000 yr BP would be an appropriate date for Layer 11, the layer said by Poulianos to correlate with the deposits associated with the skull; but this stratigraphical correlation is difficult to prove over the distance involved in the cave. Various other claims relate to the occurrence of fire at one million years BP, the discovery of the true entrance to the cave used by Petralona man and the recovery of fragments of the Petralona man's postcranial skeleton from the 'Mausoleum' area. Of the latter claim, 1 can speak personally, having been allowed to examine, with several others, the supposed postcranial fragments. We agreed that there was no single identifiable fragment of this sample that was human. The remaining fragments were too small for either identification or attribution.

In anthropological terms, the quarrels that this site has provoked have all the makings of a Greek tragedy as harrowing and as long as the Medea of Euripedes performed so well for the delegates at the open-air theatre at the site. Indeed, the site and the situation now require a cool and informed assessment, perhaps by a commission under the chairmanship of Jan Jelinek, the newly elected President of the European Anthropological Association. Such a commission could consist of an internationally respected small group including a palaeontologist, a palaeolithic archaeologist, a palaeoanthropologist, a cave stratigrapher and a geochronologist. Their task could be to examine the bones, the tools, the cave and the claims made for them.

Make no mistake, however, Aris Poulianos and his son, Nickos Poulianos, are to be congratulated on the progress that they have made at the site, but they must also accept that today such a tremendous enterprise must be a team effort. No single researcher can encompass all the disciplines that the rigorous investigation of a site demands today, neither can one man have the time and resources to 'go it alone' successfully.

The view that emerged from the conference was quite clear in that the Petralona specimen is an extremely important skull, almost certainly of Middle Pleistocene age, and of critical importance in documenting the transition from the Homo erectus stage of human evolution to the Homo sapiens stage in Europe. We owe it to Petralona man, therefore, to gain from the skull and the site every scrap of evidence available to us by the use of modern methods and scientific cooperation.
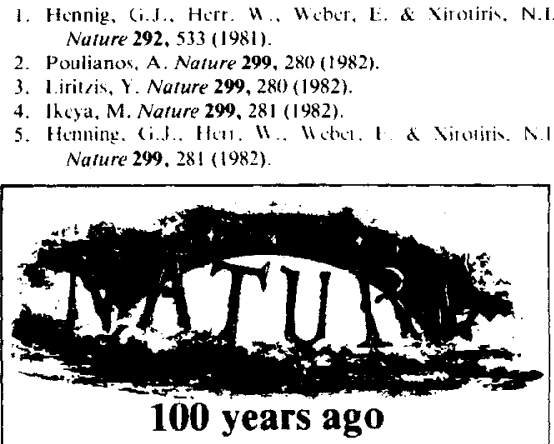

EI.ABCRATE preparations were made in various parts of America to observe the transit of Venus yesterday. The Western Union Telegraph, to facilitate observations, arranged to transmit Washington time wherever desired, in order to secure accuracy in recording results. Some enthusiastic astronomers had proposed general prayer in the churches on Sunday last for clear weather. From Nature 27, 132, 7 December 1882 